\title{
The effect of motivation and hygiene factors on employees' work motivation in textile and apparel enterprises
}

\author{
Hau Van Pham ${ }^{a^{*}}$ and Hanh Thi Hai Nguyen ${ }^{b}$
}

${ }^{a}$ Faculty of Management Science, National Economics University, Hanoi, Vietnam

${ }^{b}$ Faculty of Human Resources Economics and Management, National Economics University, Hanoi, Vietnam

CHRON I C L E

\begin{tabular}{l}
\hline Article history: \\
Received: February 19, 2020 \\
Received in revised format: \\
March 252020 \\
Accepted: April 20, 2020 \\
Available online: \\
April 20, 2020 \\
\hline Keywords: \\
Work motivation \\
Motivation factors \\
Hygiene factors and employees \\
\hline
\end{tabular}
A B S T R A C T

This study was conducted to evaluate the factors affecting work motivation. Ten dimensions of the motivation factors in this study were determined as Achievement, Recognition, Job characteristics, Responsibility, Advancement, and hygiene factors included Work conditions, Supervision, Company Policies, Salary and Relationships used for the proposed model. The research methodology was conducted in a survey with participation of 200 respondents from 15 enterprises. The data was analyzed by using descriptive statistics, factor analysis and regression. The empirical results show that Company policies significantly impacted on Work motivation, whereas Job characteristic had no impact on Work motivation. Finally, the study recommended some solutions to help companies improve their performance.

\section{Introduction}

Along with technology devices, textile and apparel is the main export sector of Vietnam in over the course of 10 years since 2010. In 2019, apparel products are exported to over 200 countries and territories with the export turnover of 20 billion US; making up $20 \%$ of total export turnover of Vietnam and $12 \%$ of the national GDP. Vietnam has become one of the fastest growing countries in textile and apparel export with annual growth rate in the 2009-2019 period reaches $14.5 \%$. There are 8,000 textile and apparel enterprises in the country; attracting more than 3 million workers, accounts for about $25 \%$ labor in the industrial sector in Vietnam. According to Nhung (2018), every 1.0 billion US of textile and apparel export could create jobs for 150-200 thousand employees, of which there are 100 thousand employees in the apparel businesses and 50-100 thousand employees in the other supporting businesses. It showed that employees working in this industry have many benefits from such enterprises provided to them. In order to engage with companies, employees have to have work motivation and job satisfaction. Motivation may be seen as the set of forces that led people to behave in different positive ways (Pinder, 2014). Productivity and quality of work depends on the motivation level of workforce working in the company, where oriented employees are usually highly motivated. Deeply understanding the demands of employees and motivating them is not an easy task in the frequent changing environment (Muhammad, 2012). According to Watson (1994) business has come to realize that a motivated and satisfied workforce can deliver powerfully to the bottom line. Since employee performance is a joint function of ability and motivation, one of management's primary tasks, therefore, is to motivate employees to perform to the best of their ability (Moorhead \& Griffin, 1998). In order to measure work motivation of employees, Herzberg (1959) discovered a model called two-factor model, which is included motivation factors and hygiene factors. This model has been applied to many researches and variety of discipline, and many enterprises were successful in evaluating their employees' work motivation (Lundberg et al., 2009). In this study, we will use this model to evaluate the effect of motivation factors and hygiene factors on work motivation of employees in textile and apparel enterprises in Vietnam industry. Thereby, we recognize that factors have different effects on indicators reflecting work motivation. Research data was collected from reliable sources and 
clear citations with high commitment of research group. To ensure the representativeness, completeness, and reliability of the collected samples, the study period selected in 2019 when all textile and apparel industry got the highest revenue and interests and the number of employees reached the highest. At that time, the average income per labor was a half compared to 2018 , which attracted a large number of labors working in this industry. We conducted on 15 enterprises and 200 samples to get the best estimate. On that basis, we set up a regression model for analysis and verification with the help of specialized software SPSS 20.0. The primary objective of this study is to investigate the effect of factors on work motivation and measure level of impacts. To achieve the goals set out, in this study, the authors used quantitative methods, built regression models to show the relationship between factors and work motivation; in which work motivation is dependent variable; motivation factors and hygiene factors are dependent variables, with the help of specialized software SPSS 20.0.

\section{Literature Review and Hypothesis}

Theoretically, Bedian (1993) defined that motivation is an attempt to achieve the targets, while Mitchell (1973) showed that motivation is the degree to which an individual archiving to engage in their own behavior. Also, Lawler and Maier (1973) concluded motivation as individuals' yearning and voluntary. There are many theories discovered and conducted to make basis for work motivation such as Maslow's hierarchy of needs, ERG theory of motivation of Clayton Alderfer, Vroom's Expectancy Theory, The Porter and Lawler theory of motivation, John Stacey Adams' equity theory, Skinner's behavioral theory. As pointed by Vroom (1964), motivation is derived from the Latin word 'movere', which means 'to move'. It is an internal force, dependent on an individual's needs which drive them to achieve. Schulze and Steyn (2003) stated that in order to understand the behavior of people in the workplace, managers or supervisors must be aware of the concept of need or motivation, which will help move employees and their actions. According to Robins and Paulhus (2001), motivation is a process of satisfying needs, meaning that when an individual's needs is satisfied or motivated by certain factors, that individual will exert a remarkable effort to achieve organizational goals. Herzberg (1959) divided employees' need into two main groups affected to employees' behavior in different aspects. Employees feel dissatisfied with their work when they are worried about the working environment. Conversely, employees feel satisfied with their jobs when they are passionate about their jobs. Herzberg divided into two main factors which is motivation factors and hygiene factors.

\subsection{Motivation factors}

Motivation factors give positive satisfaction, arising from intrinsic conditions of the job itself, such as recognition, achievement, or personal growth (Frost, 1976). According to Herzberg's theory, motivation factors, or motivators, are intrinsic to the job and lead to positive attitudes towards the job because they satisfy the 'need for growth or self-actualization' (Herzberg, 1966). Motivation factors are related to a person's job satisfaction and include advancement, the work itself, possibility of growth, responsibility, recognition and achievement (Herzberg, 1966). The following is a brief explanation of each of the motivation factors (Herzberg, 1966; Adair, 2006). Motivating factors for positive satisfaction, arising from the internal conditions of the job itself, such as recognition, achievement or personal growth (Frost, 1976). According to Herzberg's theory, motivational factors are intrinsic to the work and lead to a positive attitude towards the job because they satisfy the need for growth or self-implementation (Herzberg, 1966). Motivation factors are related to a person's job satisfaction and include promotion, job itself, ability to grow, responsibility, recognition and achievement (Herzberg, 1966). The following is a brief explanation of each driving factor (Herzberg, 1966; Adair, 2006).

Achievement: According to Crandall (1963), the desire to perform proficiently in performance situations is a basic and pervasive motivation in human experience. The popularity of this need is evident, not only in the towering intellectual products of Spinoza or Einstein, but also in the first faltering efforts of an unpaid toddler or a Kindergarten kid to print his name. For most people, philosophers or carpenters, children or adults achieve the desired achievement goals and the consent of the servant (whether from themselves or others) accrues to the Achievements, are important sources of personal satisfaction and security. For achievement orientations, it is hypothesized that, for both men and women, (1) all three achievement orientations will lead individuals to participate in the work and (2) dropouts will more socially acceptable than others (Ewing, 1982). Herzberg et al. (1966) pointed that a job must give an employee a sense of achievement, which will provide a proud feeling of having done something difficult but worthwhile. Achievement in working can make employees feel motivational to work and make them more interested in their own jobs.

\section{H1: Achievement positively influences on Work Motivation.}

Recognition: According to Hunt and Hill (1969) employee recognition is an employee's recognition of exemplary performance. Basically, the goal of recognizing employees in the workplace is to reinforce specific behaviors, practices or activities that lead to better performance and positive business results. The recognition of works is one of the most important stages in the work's handling and the awareness of the building has a great impact on the interests of workers. Works' cognizance should follow some principles to ensure it could not deviate from the legislation intended (Cao, 2010). Supervisors and peers should provide an employee with praise and recognition of their successes (Herzberg, 1959). Therefore, recognition will be affected to employees' motivation, which make them more excited in working. 
Job characteristics: The study of Lawler and Hall (1970) demonstrated satisfaction with job characteristics such as the degree of work control allows the holder and the level to be considered consistent with the owner's ability to value. Intrinsic motivation is more strongly related to measure job characteristics, but less relevant to both effort and performance than to satisfaction or participation. The job should give enough of a challenge to keep employees motivated. Duke and Sneed (1989) showed that job characteristic could be considered as a high indicator of work motivation. In conclusion, job characteristic has a significant contribution to employees' motivation.

\section{H3: Job characteristics positively influences on Work Motivation.}

Responsibility: A study of Dose and Klimoski (1995) pointed that changing trends and the nature of the workforce dictate increasing employee personal responsibility and expanded the use of self-management practices. Working through some of intellectual roadblocks may enable a reassembling of responsibility as the basis for workplace democracy (Ellerman, 2000). Employees should own their work and hold themselves responsible for this completion.

\section{H4: Responsibility positively influences on Work Motivation.}

Advancement: A promotion is a form of recognition for employees who make significant and effective work contributions. Igbaria and Baroudi (1995) indicated that job performance plays an important role in influencing an individual's promotion. The career advancement could lead to a higher salary and income for employees, and be responsible for a higher position.

\section{H5: Advancement positively influences on Work Motivation.}

\subsection{Hygiene factors}

Hygiene factors do not bring positive satisfaction or lead to higher motivation, although dissatisfaction is the result of their absence. The term "hygiene" is used in the sense that these are maintenance factors. These are external factors to the job itself and include aspects such as company policies, supervisory practices or wages/salaries. Herzberg (2014) called hygiene elements "KITA" elements, which is an acronym for "kick in ass", the process of providing incentives or threatening sanctions to get someone to do something. Herzberg stated that hygiene factors are external factors of the job, and if so, leads to the prevention of job dissatisfaction because hygiene factors respond to the environment and the workplace because need to avoid discomfort (Herzberg, 1966). Hygiene factors work to reduce employee job dissatisfaction. Hygiene factors are related to the context of the job itself, and include interpersonal relationships, wages, policies and corporate governance, relationships with supervisors and working conditions (Herzberg, 1966). The following is a brief summary of hygiene factors (Herzberg, 1966; Adair, 2006):

Company policies: Company policy is a guide to help employers address their responsibilities, health, safety and employee interaction. Policies are also guidelines for legal issues, legal requirements and any circumstances that can lead to serious consequences. Adair (2006) pointed out that corporate policies help improve the health of employees, treat them fairly and to ensure that companies comply with laws and regulations. This includes descriptions of full or incomplete organization and management policies and guidelines. This factor relates to good or poor organizational policies affecting employees.

\section{H6: Company policies positively influences on Work Motivation.}

Supervision: Herzberg (1966) and Adiar (2006) reported that Supervision is related to the capacity or incompetence, and the fairness or unfairness of the supervisor or supervisor. This includes supervision of a supervisor willing to delegate responsibility or teaching, impartiality and work knowledge. A good supervisor, or an access to supervision, is important to improve employee satisfaction. Poor leadership or management can reduce job satisfaction at the workplace. Monitoring aims to provide responsibility for both supervisors and supervisors of discovery and implementation practices. It also enhances and provides additional evidence for management and annual performance evaluation. Monitoring focuses specifically on developing supervisors in a way that focuses on achieving better results for service users and their careers.

\section{H7: Supervision positively influences on Work Motivation.}

Work conditions: Devine (2009) pointed that structural work conditions among parents such as job hours, schedule, and satisfaction are associated with food choice coping strategies with importance for work quality. Findings have implications for worksite interventions but need examination in a larger sample. Following to Gallie and Russell (2009) work conditions are found to play a larger role than family characteristics in accounting for work-family conflict, both in the country level models and in the pooled models. Herzberg (1959) concluded these factors involve the physical surroundings of the job, and 
whether there are good or poor facilities. Working conditions may include the amount of work, space, ventilation, tools, temperature and safety. A good environment, as opposed to a poor environment, makes employees satisfied and proud.

H8: Work conditions positively influences on Work Motivation

Salary: It is undeniable that sales managers always use high salaries to attract, retain and motivate employees. Robins and Paulhus (2001) reported that money could be considered as a scorecard through which workers can assess how important an organization is to them compared to other organizations. However, there have been many inappropriate views on the role of wages. According to Maslow's hierarchical demand theory, wages are linked to lower-level needs, such as physical and security needs. Maslow (1954) states that once lower order demand is met, higher order demand will take precedence, so an increase in wages does not motivate employees further. In order to improve job satisfaction and performance levels of employees, managers must work on motivators by creating opportunities for advancement and career development because workers value Those who are more motivated are hygiene factors (Ramlall, 2004). Blair and Kochan (2002) argue that money only leads to temporary obedience of workers, and it does not succeed in changing workers' attitudes and behaviors in the long run. They further pointed out that money only motivates workers to seek further rewards, and in the process, it can undermine their intrinsic benefits at work. Wages include all forms of compensation at a workplace, such as wage increases or increases, or unrealized expectations for wages or increases or decreases. Hospital policies should be clear about pay increases and bonuses at the workplace.

\section{H9: Salary positively influences on Work Motivation.}

Relationships: Sias et al. (2012) has shown that workplace relationships are unique interpersonal relationships with significant implications for the individuals in those relationships and the organizations in which they relate. Relationships exist and develop. The workplace relationship directly affects the ability of workers and drives success. These connections are multifaceted, can exist inside and outside the organization, and both positive and negative. Such a disadvantage lies in the nonexistence of workplace relationships, which can lead to feelings of loneliness and social isolation. Workplace relationships are not just limited to friendship, but also include superior, romantic and family relationships. The Hawthorne effect evolved from a series of studies. The theory says that an individual will behave differently than normal due to the perception of an individual being tracked. Specifically, in McGregor's X and Y theory, it says that a manager's approach affects workers' results. Individuals who receive attention from their superiors will have a positive feeling when they receive special treatment. Specifically, they feel that the attention they are receiving is unique from the attention that other employees are receiving (Lee-Kim, 2006). A basic understanding of the superior-subordinate relationship rests on the basis that superiors' habits tend to create a productive or counterproductive environment (Kohn, 2005).

H10: Relationships positively influences on Work Motivation

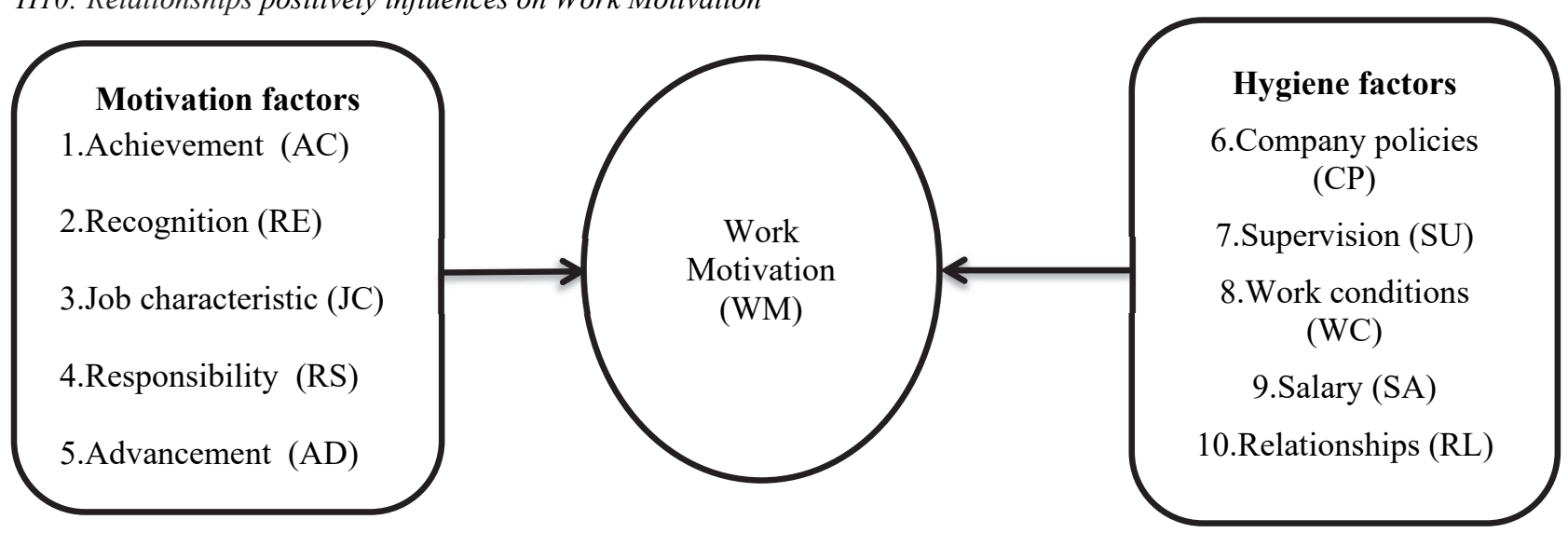

Fig 1. Conceptual Model

\section{Methodology}

This research paid high attention on work motivation. Quantitative data collection method is used for this study with using numbers, mathematics, statistics and vice versa in order to measure precisely research data with target of accepting or rejecting research hypotheses and answer research questions. Most of the questions in the survey were designed based on five point Likert scale, respondents rate the items on the five point scale, on which 1 and 5 indicated "strongly disagree" and "strongly agree" respectively. The survey questionnaires were directly sent to employees who are working in these companies. Employees are in various positions from managers to workers to ensure the diversity of samples. Participants are both males and females. To get more consistent, only employees has been working over two years will be nominated. This research applied the convenience sampling method with 200 respondents from 15 enterprises were asked to fill in questionnaire. Fig. 2 presents 
personal characteristics of the participants in our survey. As we can observe from the figure, $52 \%$ of the participants were female and $48 \%$ of them were male. In addition, nearly, $85 \%$ of them aged less than 40 while $63 \%$ of them were just workers.

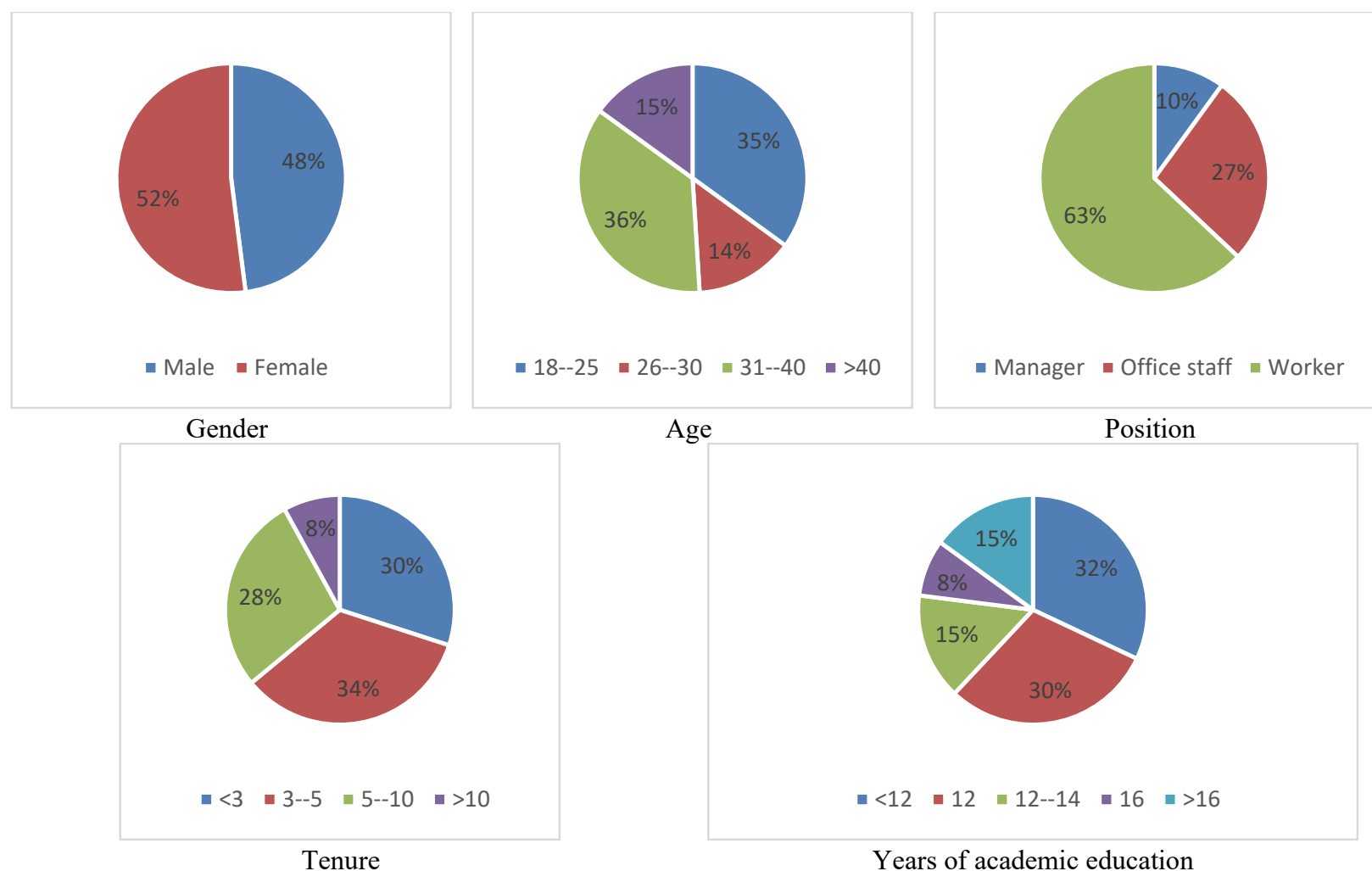

Fig. 2. Personal characteristics of the participants

\section{Results}

\subsection{Factor analysis and Reliability}

Exploratory Factor Analyses (EFA) were conducted with group of variables: 30 items of the independent variables and 3 items of the dependent variables. There are many factor extraction methods, the factor extraction method used in this study is the Principal Components method with perpendicular rotation (varimax). Moreover, descriptive statistics were used to illustrate the demographic data and other variables. Multiple regressions were applied to determine the effects of the independent variables on the dependent variables (Bahadori et al., 2015). The results of EFAs showed that Kaiser-Meyer-Olkin measure of sampling adequacy was 0.776 for independent variables, according to study of Tabachnick and Fidell (1996) the data were suitable for analysis. The Bartlett's test off sphericity, significant $=0.000<0.05$ which means the factor analysis was appropriate.

\section{Table 1}

Result of factor analysis EFAs

\begin{tabular}{cll}
\hline Kaiser-Meyer-Olkin Measure of Sampling Adequacy. & .776 & \\
Bartlett's Test of Sphericity & Approx. Chi-Square & 2293.647 \\
& df & 990 \\
& Sig. & .000 \\
\hline
\end{tabular}

The study provides that all components extracted and all eigenvalues are greater than 1 . According to Hoang Trong and Chu Nguyen Mong Ngoc (2008), the eigenvalue quantity represents the amount of variability explained by the factor, factors with eigenvalue less than 1 will be excluded from the analysis model because there is no summary effect information better than an original variable. Table 2 of model summary shows the value of R-square of factors on work motivation (WM) is 0.659 , which means that six factors can explain $65.9 \%$ the variation of work motivation (WM). The Cronbach's coefficients ranged from 0.644 to 0.818 proving the consistency of these variables. 
Table 2

Assess the appropriateness of the model

\begin{tabular}{lccccc}
\hline Model & $\mathrm{R}$ & $\mathrm{R}$ Square & Adjusted R Square & Std. Error of the Estimate & Durbin-Watson \\
\hline 1 & .812 & .659 & .636 & .32123 & 1.799 \\
\hline
\end{tabular}

Table 3

Summary of independent variables

\begin{tabular}{llllll}
\hline Names & Number of items & Cronbach's alpha & Names & Number of items & Cronbach's alpha \\
\hline Achievement (AC) & 3 & 0.818 & Company policies (CP) & 3 & 0.808 \\
Recognition (RE) & 3 & 0.738 & Supervision (SU) & 3 & 0.772 \\
Job characteristic (JC) & 3 & 0.750 & Work conditions (WC) & 3 & 0.665 \\
Responsibility (RS) & 3 & 0.644 & Salary (SA) & 3 & 0.742 \\
Advancement (AD) & 3 & 0.770 & Relationships (RL) & 3 & 0.8 \\
\hline
\end{tabular}

\subsection{Regression Model}

ANOVA analysis result with Sig. value $=0.00<0.05$ shows that the variables included in the regression model have an impact on the dependent variable. Based on the model suitability standards proposed by Gujarati (2009); Hill et al. (2012) we can see that the research model is highly relevant for explaining the behavior of the dependent variable.

Table 4

The results of ANOVA analysis

\begin{tabular}{llllll}
\hline Model & Sum of Squares & df & Mean Square & F & Sig. \\
\hline Regression & 12.604 & 7 & 1.575 & 17.267 & .000 \\
Residual & 11.536 & 112 & .103 & & \\
\hline Total & 24.140 & 119 & & & \\
\hline
\end{tabular}

Table 5

$\underline{\text { Regression analysis result }}$

\begin{tabular}{|c|c|c|c|c|c|c|c|}
\hline \multirow[b]{2}{*}{ Model } & \multicolumn{2}{|c|}{$\begin{array}{c}\text { Unstandardized } \\
\text { Coefficients }\end{array}$} & \multirow{2}{*}{$\begin{array}{c}\begin{array}{c}\text { Standardized } \\
\text { Coefficients }\end{array} \\
\text { Beta }\end{array}$} & \multirow[b]{2}{*}{$\mathrm{T}$} & \multirow[b]{2}{*}{ Sig. } & \multicolumn{2}{|c|}{ Collinearity Statistics } \\
\hline & $\mathrm{B}$ & Std. Error & & & & Tolerance & VIF \\
\hline (Constant) & .054 & .278 & & .303 & .000 & & \\
\hline $\mathrm{AC}$ & .254 & .025 & .368 & 13.064 & .001 & .834 & 1.131 \\
\hline $\mathrm{RE}$ & .113 & .023 & .151 & 5.812 & .000 & .761 & 1.031 \\
\hline $\mathrm{JC}$ & -.143 & .018 & -.107 & -7.335 & .098 & .815 & 1.105 \\
\hline $\mathrm{RS}$ & .087 & .014 & .124 & 4.474 & .002 & .865 & 1.172 \\
\hline $\mathrm{AD}$ & .090 & .022 & .139 & 4.629 & .002 & .752 & 1.019 \\
\hline $\mathrm{CP}$ & .273 & .029 & .426 & 9.484 & .000 & .937 & 1.005 \\
\hline SU & .165 & .026 & .287 & 6.395 & .000 & .940 & 1.113 \\
\hline WC & .199 & .038 & .230 & 5.248 & .000 & .988 & 1.045 \\
\hline SA & .192 & .043 & .198 & 4.473 & .000 & .971 & 1.123 \\
\hline $\mathrm{RL}$ & .205 & .047 & .193 & 4.398 & .000 & .980 & 1.056 \\
\hline
\end{tabular}

The VIF of the independent variables ranges from $1.019-1.172$, all less than 10 , so there is no multi-collinear phenomenon between the independent variables in the model. The standardized linear regression equation between working motivation and influencing factors is:

$W M=0.054+0.368 \times A C+0.151 \times R E-0.107 \times J C+0.124 \times R S+0.139 \times A D+0.426 \times C P+0.287 \times S U+0.23 \times W C+$ $0.198 \times S A+0.193 \times R L$.

In the model, the blocking coefficient of 0.054 , the specific regression coefficients between variables $\mathrm{AC}, \mathrm{RE}, \mathrm{JC}, \mathrm{RS}, \mathrm{AD}, \mathrm{CP}$, SU, WC, SA, RL are respectively $0.368,0.151,-0.107,0.124,0.139,0.426,0.287,0.23,0.198,0.193$. The variable CP has the greatest impact on the working motivation of workers, followed by the variables AC, RE, RS, AD, SU, WC, SA, RL particularly the variable JC has the opposite impact on the working motivation. 
Table 6

Test results of hypotheses in the model

\begin{tabular}{|c|c|c|}
\hline Hypothesis & Content & Conclusion \\
\hline H1 & Achievement positively influences on Work Motivation & Accepted $(\mathrm{b} 1=0.368>0$ and sig. $=0.001<0.05)$ \\
\hline H2 & Recognition positively influences on Work Motivation & Accepted $(\mathrm{b} 2=0.151>0$ and sig. $=0.000<0.05)$ \\
\hline H3 & Job characteristics positively influences on Work Motivation & Rejected $(\mathrm{b} 3=-0.107<0$ and sig. $=0.098>0.05)$ \\
\hline H4 & Responsibility positively influences on Work Motivation & Accepted $(\mathrm{b} 4=0.124>0$ and sig. $=0.002<0.05)$ \\
\hline H5 & Advancement positively influences on Work Motivation & Accepted $(\mathrm{b} 5=0.139>0$ and sig. $=0.000<0.05)$ \\
\hline H6 & Work conditions positively influences on Work Motivation & Accepted $(\mathrm{b} 6=0.426>0$ and sig. $=0.000<0.05)$ \\
\hline H7 & Supervision positively influences on Work Motivation & Accepted $(\mathrm{b} 7=0.287>0$ and sig. $=0.000<0.05)$ \\
\hline H8 & Company policies positively influences on Work Motivation & Accepted $(\mathrm{b} 8=0.23>0$ and sig. $=0.000<0.05)$ \\
\hline H9 & Salary positively influences on Work Motivation & Accepted $(\mathrm{b} 9=0.198>0$ and sig. $=0.000<0.05)$ \\
\hline H10 & Relationships positively influences on Work Motivation & Accepted $(\mathrm{b} 10=0.193>0$ and sig. $=0.000<0.05)$ \\
\hline
\end{tabular}

From the table of multiple regression results, we can draw conclusions about the results of testing hypotheses in the research model as follows:

The influencing factors include AC, RE, RS, AD, SU, WC, SA, RL, since all have beta coefficient greater than 0 and sig. are less than 0.05 . Factor that do not affect the working motivation of employees is the JC factor group because of beta $=-0.107$ $<0$ and sig value. $=0.098>0.05$.

\section{Conclusion and Recommendation}

The results have shown there were 10 factors influencing on work motivation of employees; namely Achievement, Recognition, Job characteristics, Responsibility, Advancement, Work conditions, Supervision, Company Policies, Salary and Relationships. In our survey, 9 factors have maintained statistically significant effect, which are Achievement, Recognition, Responsibility, Advancement, Work conditions, Supervision, Company Policies, Salary and Relationships but Job characteristics did not provide meaningful impact on work motivation. Company policies has maintained the greatest impact on working motivation, followed by is Achievement. With the conclusion, we have proposed some recommendations for textile and apparel companies to improve their work staff:

Firstly, Enterprises need to develop a separate document on detailed regulations on salary calculation, pay time, conditions for salary increase, and send a written document to each department and disseminate to all employees. For each position, there should be specific criteria and requirements to accurately evaluate the performance of employees. In addition, it is also necessary to supplement the seniority criteria for working to perform the salary scoring. It is crucial to build for each position required to work, evaluate the results of daily work of employees such as timekeeping as a basis for calculating salaries for employees as well as recording achievements, declaring positive, reward the parts, individuals with good work results. Secondly, restructuring the control department, established a separate department to monitor the production process as well as purchase and sale of raw materials and finish products at the company. Completing the monitoring process appropriately, avoiding leadership duplication with other functional departments. Developing a job description and a reasonable competency framework for the supervisor so that they know what they need to do and what they need to be able to complete their work. Having a plan to control the production process as well as the activities of importing and exporting raw materials and finished products regularly in each day and each working shift. Moreover, superiors regularly visit activities in departments, workshops in the factory so that they can be closer to workers, understand them more, and receive suggestions and solve their questions. It is vital to regularly organize meetings, to gather employees' comments on the company's policies, working conditions in order to help managers make reasonable improvements to bring about satisfaction, trust for employees for the company as well as closing the gap between superiors and subordinates. Last, developing a clear job description with a competency framework for each position so that employees understand what they do, need the knowledge, skills and attitude to work. Managers and heads of divisions need to understand the characteristics and working ability of each member they manage so that they can assign them suitable jobs, helping them to promote to the best of my ability to work.

\section{References}

Adair, J. E. (2006). Leadership And Motivation: The Fifty-Fifty Rule And The Eight Key Principles Of Motivating Others. Kogan Page Publishers.

Bahadori, M., Raadabadi, M., Teymourzadeh, E., \& Yaghoubi, M. (2015). Confirmatory factor analysis of the herzberg job motivation model for workers in the military health organizations of Iran. Journal of Military Medicine, 17(2), 65-71.

Bedian, A. G. (1993). Management (3 ${ }^{\text {rd }}$ Ed.) Dryden Press. New York.

Blair, M. M., \& Kochan, T. A. (Eds.). (2002). The new relationship: Human capital in the American corporation. Brookings institution press.

Cao, Y. C., Ma, Y. B., \& Wen, D. S. (2010). On the principles of the recognization of works' injury. Journal Of Yanshan University (Philosophy And Social Science Edition), 1, 19.

Crandall, V. J. (1963). Achievement. 
Dose, J. J., \& Klimoski, R. J. (1995). Doing the right thing in the workplace: Responsibility in the face of accountability. Employee Responsibilities and Rights Journal, 8(1), 35-56.

Duke, K. M., \& Sneed, J. (1989). A research model for relating job characteristics to job satisfaction of university foodservice employees. Journal of The American Dietetic Association, 89(8), 1087-1091.

Ellerman, D. (2000). Responsibility and workplace democracy. Peace Review, 12(2), 189-195.

Ewing, M. E. (1982). Achievement orientations and sport behavior of males and females.

Frost, P. J., \& Mahoney, T. A. (1976). Goal setting and the task process: I. An interactive influence on individual performance. Organizational Behavior and Human Performance, 17(2), 328-350.

Gallie, D., \& Russell, H. (2009). Work-family conflict and working conditions in Western Europe. Social Indicators Research, 93(3), 445-467.

Gujarati, D. N. (2009). Basic Econometrics. Tata McGraw-Hill Education.

Herzberg, F. Mausner, B., \& Snyderman, B.P. (1959). The Motivation To Work.

Herzberg, F. (1959). Herzberg's Motivation-Hygiene Theory (Two Factor Theory). Arab British Academy For Higher Education: London, Uk, 1-2.

Herzberg, F. (1966). Work And The Nature Of Man, Chapter 6.

Herzberg, F. (1971). The Motivation-Hygiene Theory. Work And The Nature Of Man, 4.

Herzberg, F. (January-February 1968). One more time: How do you motivate employees?. Harvard Business Review. 46(1), 53-62.

Hunt, J. G., \& Hill, J. W. (1969). The new look in motivation theory for organizational research. Human Organization, 28(2), 100-109.

Igbaria, M., \& Baroudi, J. J. (1995). The impact of job performance evaluations on career advancement prospects: An examination of gender differences in the is workplace. Mis Quarterly, 19(1), 107-123.

Kohn, S. E., \& O'connell, V. D. (2005). 6 Habits Of Highly Effective Bosses. Jaico Publishing House.

Lawler, E. E., \& Hall, D. T. (1970). Relationship of job characteristics to job involvement, satisfaction, and intrinsic motivation. Journal Of Applied Psychology, 54(4), 305.

Lawler III, E. E., \& Suttle, J. L. (1973). Expectancy theory and job behavior. Organizational Behavior and Human Performance, 9(3), 482-503.

Lee-Kim, J. (2007). Book Review: 6 Habits of Highly Effective Bosses. Business Communication Quarterly, 70(1), $104-108$.

Lundberg, C., Gudmundson, A., \& Andersson, T. D. (2009). Herzberg's two-factor theory of work motivation tested empirically on seasonal workers in hospitality and tourism. Tourism Management, 30(6), 890-899.

Mitchell, T. R. (1973). Motivation and participation: An integration. Academy of Management Journal, $16(4), 670-679$.

Moorhead, G. \& Griffin, R.W. (1998). Organizational Behavior: Managing People And Organizations (5th Ed.). Boston: Houghton Mifflin.

Muhammad, G., \& Memon, U. (2012). Determinants of employee motivation-A case study of Afroze textile industries limited, Karachi, Pakistan. Iosr Journal Of Business And Management, 4(3), 22-25.

Nhung, T. T. B., \& Thuy, T. T. P. (2018). Vietnam's Textile And Garment Industry: An Overview.

Pinder, C. C. (2014). Work Motivation In Organizational Behavior. Psychology Press.

Ramlall, S. (2004). A review of employee motivation theories and their implications for employee retention within organizations. Journal Of American Academy Of Business, 5(1/2), 52-63.

Robins, R. W., \& Paulhus, D. L. (2001). The Character Of Self-Enhancers: Implications For Organizations.

Sias, P. M., Gallagher, E. B., Kopaneva, I., \& Pedersen, H. (2012). Maintaining workplace friendships: Perceived politeness and predictors of maintenance tactic choice. Communication Research, 39(2), 239-268.

Steyn, G. M., \& Schulze, S. (2003). Assuring Quality Of A Module In Human Resource Management: Learners' perceptions. Education, 123(4).

Tabachnick, B. G., \& Fidell, L. S. (1996). Using Multivariate Statistics. Northridge. Cal.: Harper Collins.

Trong, H., \& Ngoc, C. N. M. (2008). Data analysis with SPSS. Ho Chi Minh City: Hong Duc Publishing House, (1).

Vroom, V. H. (1964). Work And Motivation.

Watson, T. (1994). Linking employee motivation and satisfaction to the bottom line. CMA magazine, 68(3), 4-4.

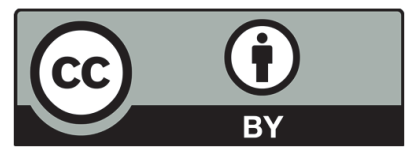

(C) 2020 by the authors; licensee Growing Science, Canada. This is an open access article distributed under the terms and conditions of the Creative Commons Attribution (CC-BY) license (http://creativecommons.org/licenses/by/4.0/). 